Article

\title{
Investigating the Utility of Fabric Phase Sorptive Extraction and HPLC-UV-Vis/DAD to Determine Antidepressant Drugs in Environmental Aqueous Samples
}

\author{
Cristina Jiménez-Holgado ${ }^{1}$, Christoforos Chrimatopoulos ${ }^{1}$, Vassilis Stathopoulos ${ }^{2} \mathbb{C}$ and \\ Vasilios Sakkas ${ }^{1, *}$ \\ 1 Chemistry Department, University of Ioannina, 45110 Ioannina, Greece; crijimhol@gmail.com (C.J.-H.); \\ xrimatopoulosxris@gmail.com (C.C.) \\ 2 General (Core) Department, National and Kapodistrian University of Athens, 34400 Psachna Campus, Evia, \\ Greece; vasta@uoa.gr \\ * Correspondence: vsakkas@uoi.gr; Tel.: +30-2651008303
}

Received: 15 May 2020; Accepted: 1 July 2020; Published: 8 July 2020

check for updates

\begin{abstract}
Depression is considered to be one of the most prevalent mental disorders in humans. Antidepressant drugs are released in large concentrations and cause adverse effects on the environment and/or human health. Fabric Phase Sorptive Extraction (FPSE), a contemporary solid sorbent-handling technique, is a quick, sensitive, and simple analytical process. This paper describes a micro-extraction FPSE procedure coupled with High-Performance Liquid-Chromatography-Photodiode Array Detection (FPSE-HPLC-DAD) for the simultaneous extraction and analysis of five antidepressants, namely citalopram, clozapine, mirtazapine, bupropion and sertraline. Three fabric media (Whatman Cellulose filter, Whatman Microfiber Glass filter and Polylactic acid disks) and two different sol-gel sorbents (polyethylene glycol (PEG 300), alongside poly(ethylene glycol)-block-poly(propylene glycol)-block-poly(ethylene glycol) (PEG-PPG-PEG 5.800)) were tested. The best FPSE device was observed to be the microfiber glass filter coated with PEG 300 sol-gel sorbent. In addition, the parameters that affect the efficiency of the process (FPSE media and sorbents, sample $\mathrm{pH}$, extraction time, elution time, etc.) were optimized. The proposed methodology displays a linear range with absolute recovery values higher than $60 \%$, RSD $\%$ of less than $13 \%$ and LOQs in the range between 1.9-10.7 $\mu \mathrm{g} \cdot \mathrm{L}^{-1}$. Finally, the method was applied in hospital and urban effluents and lake water samples, but none of the analytes were detected.
\end{abstract}

Keywords: antidepressants; determination; experimental design; emerging contaminants

\section{Introduction}

Depression (major depressive disorder) is one of the most ordinary and widespread mental diseases caused by various social, psychological, and biological factors interacting and correlating among each other. It negatively affects how someone feels, their way of thinking and how the person acts. Depending on the nature and period of the symptoms, it may cause a severe health disorder that causes restricted psychosocial function, a decreased quality of life and satisfaction, feelings of culpability or low confidence, reduced sleep or hunger, poor performance, and may even result in suicide.

The pharmacological treatment of depression began in the 1950s, with the introduction of the first-generation antidepressant drugs (ADs), such as tricyclic and tetracyclic antidepressants (TCAs), and monoamine oxidase inhibitors (MAOIs). Two decades later, the second-generation agents were 
introduced, namely selective serotonin reuptake inhibitors (SSRIs). The newest and most used antidepressants drugs appeared after the 1990s, (serotonin and norepinephrine reuptake inhibitors) [1].

A concerning overconsumption of ADs has been observed in recent years. A big variety of ADs have already been detected in the range of a few $\mathrm{ng} \cdot \mathrm{L}^{-1}$ to several tens of $\mu \mathrm{g} \cdot \mathrm{L}^{-1}$ in surface waters and wastewater [2-5]. Therefore, the identification and quantification of such drugs is now of great importance in natural water, since concentration levels up to $78.3 \mu \mathrm{g} \cdot \mathrm{L}^{-1}$ have been reported [5].

The literature has documented numerous analytical techniques for the determination of ADs. The most commonly used are high performance liquid chromatography (HPLC) coupled to UV-Vis or a mass spectrometric detector (MS) [6-13]. Gas chromatography (GC) coupled to MS [14-17] or tandem MS [18], and the capillary electrophoretic technique (CE) have also been reported [19]. A significant drawback of GC methods is the restriction of the target compound's volatility [20]. In comparison, HPLC can evaluate both volatile and non-volatile compounds, contributing to an adequately user-friendly separation technique [21].

Pretreatment of the sample is the most important step in the workflow of chromatographic analysis, since most samples are not able to be immediately injected into the chromatographic instrument. Various sample preparation approaches coupled with HPLC for the determination and preconcentration of antidepressant drugs in biological fluids have been reported. The most frequently employed techniques are liquid-liquid extraction (LLE) [22] and solid-phase extraction (SPE) techniques [23]. Fabric-Phase Sorptive Extraction (FPSE) has recently attracted the interest of the scientific community, particularly during its application for the determination of pharmaceutical compounds in biological samples [24,25].

Kabir and Furton first proposed FPSE as a two-step, novel and green sample preparation technique [26]. FPSE utilizes, as an extraction medium, a natural or synthetic fabric substrate, which is chemically coated in the form of an ultra-thin coating with a sol-gel organic-inorganic hybrid sorbent [27]. This microextraction technique is capable of extracting analytes within a wider polarity range, depending on the sol-gel's physicochemical properties. The porous network of sol-gel sorbent coating and the permeability of the fabric substratum contribute to the current method, which imitates the extraction of the solid phase. The desorption of analytes from the FPSE media into organic solvents is much more rapid without a significant chance of carryover. This technique overcomes the major drawbacks of other sorptive extraction procedures that exhibit limitations such as sample size and preparation time, system or coating damage, resistance to harsh chemical environments and organic solvents. FPSE has been widely used for the extraction and determination of different analytes from different sample matrices since its invention in 2014 [28-30].

In the present study, an easy, green and fast analytical methodology is proposed for the extraction of five psychoactive drugs that are commonly used in the treatment of mental diseases (citalopram, clozapine, mirtazapine, bupropion and sertraline) by employing FPSE coupled to High Performance Liquid Chromatography-Photodiode Array Detection (HPLC-DAD). The primary parameters affecting extraction efficiency were investigated and optimized using both univariate and multivariate experimental configurations of fractional factorial design followed by Response Surface Methodology. Finally, the applicability of the method was examined by obtaining natural water samples from wastewater treatment plants. To the best of our knowledge, FPSE has been extensively applied to environmental samples [31-34], but the extraction of antidepressants from real water samples has not been explored yet.

\section{Materials and Methods}

\subsection{Reagents}

The starting materials to be coated and used as FPSE media were Whatman microfiber glass filters of $110 \mathrm{~mm}$ and Whatman cellulose filter papers of $125 \mathrm{~mm}$ (Boston, MA, USA). The organic polymers polyethylene glycol (PEG 300) and poly(ethylene glycol)-block-poly(propylene 
glycol)-block-poly(ethylene glycol) (PEG-PPG-PEG 5.800) were purchased from Sigma-Aldrich (Athens, Greece). Solvents (dichloromethane, acetonitrile (ACN), acetone, methanol $(\mathrm{MeOH})$ and phosphoric acid) were purchased from Merck (Darmstadt, Germany). Trimethoxymethylsilane (MTMS), trifluoroacetic acid (TFA), sodium hydroxide, and hydrochloric acid were also supplied by Merck (Darmstadt, Germany).

Polylactic acid (PLA) 3D-printed disks of $0.02 \times 0.02 \times 0.0015 \mathrm{~m}$ were prepared using a Prusa i3 $3 \mathrm{D}$ printer using the fused deposition modeling (FDM) technique [35]. The printing and specimen volume filling parameters for the $3 \mathrm{D}$ printing process were modified using slicer software. All the parts were printed $\left(100 \%\right.$ filling density) using rectilinear pattern filling, on a heated bed $\left(60^{\circ} \mathrm{C}\right)$ and the nozzle (diameter $4 \mu \mathrm{m}$ ) was maintained at $200{ }^{\circ} \mathrm{C}$ during the process [36].

Antidepressants citalopram (CIT), clozapine (CLO), mirtazapine (MIRT), bupropion (BUP) and sertraline (SERT) were purchased from TCI Tokyo Chemical Industry (Tokyo, Japan). All analytes have a purity higher than $98 \%$. By dissolving the compound in methanol, stock solutions containing $1000 \mathrm{mg} \cdot \mathrm{L}^{-1}$ of each analyte were prepared, and the solutions were stored in glass-stopped bottles at $-20{ }^{\circ} \mathrm{C}$ in the dark. Standard working solutions were prepared daily. The ultrapure water used was produced by a Milli-Q system (Evoqua, Pittsburg, PA, USA).

STATISTICA 7.0 (StatSoft Inc., Tulsa, OK, USA) was used to produce the experimental matrix and to evaluate the results.

\subsection{Sample Collection}

Wastewater samples were collected from the outflow of municipal and university hospital wastewater treatment plants in Ioannina city, located in the Epirus region, NW Greece. In the municipal wastewater treatment plant (WWTP1) the wastewaters of the whole Ioannina city are deposited, with a population of more than 100,000 people. All household and industrial waste and rain waters are collected from the WWTP1, frequently surpassing the WWTP's capacity to handle this volume. In addition, wastewater from Ioannina hospital's WWTP effluent (WWTP2) was also sampled. Ioannina University Hospital is also the center of learning and applied medical science linked to the School of Medicine and School of Nursing at Ioannina University. About 45,000 patients are treated annually in the Care Clinics of the medical center. Furthermore, the hospital has a Department of Psychiatry, making it interesting to research the occurrence of psychotropic drugs in the hospital's WWTP effluent. The hospital's plant (WWTP2) sheds its treated wastewater into the urban network that eventually goes straight to the municipal WWTP; thus we have a significant interest in assessing its efficiency in order to determine the presence of ADs in the municipal WWTP.

Moreover, surface water was collected from Pamvotis Lake in Ioannina. Covering an area of $19.4 \mathrm{~km}^{2}$, Pamvotis Lake is one of the largest lakes in Greece. The pollution of the lake is due to the illegal dumping of waste from tankers, livestock and industrial plants, pesticide residues, illegal landfills, and the fact that parts of the city have not been connected to the city's wastewater network. All the samples were collected in clean amber glass bottles. Finally, the samples were transported to the laboratory immediately and placed in the refrigerator at $5{ }^{\circ} \mathrm{C}$ before extraction and analysis.

\subsection{HPLC Analysis}

To determine the selected analytes, a Thermo Fisher Scientific UltiMate 3000 HPLC system equipped with a diode array detector and Chromeleon Thermo Fischer software were used. The equipment consists of a Binary Solvent Manager (BSM), a WPS-3000SL autosampler and a column manager, all from Waters Thermo Fisher Scientific (Waltham, MA, USA). The parameters for the detection of the targeted analytes were optimized by using a standard solution of a mixture of all the compounds.

The injection volume into the chromatographic equipment was $20 \mu \mathrm{L}$, and the analytical column was a Hypersil GOLD $150 \times 4.6 \mathrm{~mm}$, with a particle size of $5 \mu \mathrm{m}$ (Thermo Scientific, Waltham, MA, USA), operating at $25^{\circ} \mathrm{C}$. 
The mobile phase consists of methanol (A) and water with $0.3 \%$ phosphoric acid (B), at $1.0 \mathrm{~mL} / \mathrm{min}$ flow in gradient mode. The gradient started at 15:85 (A:B) $(v / v)$ and increased after 3 min to 50\% methanol. The percentage of methanol increased further up to $80 \%$ after $7 \mathrm{~min}$ and the gradient returned, after $2 \mathrm{~min}$, to its initial state 15:85 (equilibrium time $3 \mathrm{~min}$ ). The whole chromatographic separation process finished in $15 \mathrm{~min}$. The parameters of the diode array detector (DAD) were chosen for the quantitative analysis of each compound. The UV detector was set at $245 \mathrm{~nm}$ for sertraline, clozapine and citalopram, at $230 \mathrm{~nm}$ for mirtazapine and at $254 \mathrm{~nm}$ for bupropion, with full spectral scanning from 200 to $400 \mathrm{~nm}$.

\subsection{Preparation of Sol-Gel Sorbent-Coated FPSE Media}

\subsubsection{Pretreatment of Media for Sol-Gel Coatings}

All fabrics chosen to produce sol-gel covered sorbents have remaining finishing additives or other contaminants that agglomerated over time on their surface, which required thorough cleaning. Additionally, the surface areas of these fabrics require activation to optimize the sol-gel sorbent loading during the polymer sorbent coating phase.

This was done after we implemented a systematic cleaning procedure. Briefly, a $95 \mathrm{~cm}^{2}(11 \mathrm{~cm}$ diameter) circular piece of the Whatman Cellulose filter was soaked with deionized water under constant sonication for $15 \mathrm{~min}$, followed by $\mathrm{NaOH}$ treatment $(1.0 \mathrm{M}, 1 \mathrm{~h})$ and then $\mathrm{HCl}(0.1 \mathrm{M}, 01 \mathrm{~h})$, under sonication, respectively. After each one of these three cleaning steps the fabric media were washed with a profuse amount of deionized water. The media were then left to dry in ambient air at room temperature for $24 \mathrm{~h}$, following the coating step. This procedure was followed to increase the availability of all the hydroxyl groups of the cellulose chemical structure that lead to more chemical reactions with the sol-gel inorganic-organic network.

Almost the same procedure was adopted for the Whatman Microfiber Glass filter pretreatment to activate the surface silanol groups. The difference with the abovementioned procedure was that the pretreatment time with $\mathrm{NaOH}(1.0 \mathrm{M})$ and then $\mathrm{HCl}(0.1 \mathrm{M})$ was for $8 \mathrm{~h}$, respectively.

PLA was treated with a mixture of $0.25 \mathrm{M} \mathrm{NaOH} / \mathrm{EtOH}$ for $4 \mathrm{~h}$ to improve its hydrophilicity and cell affinity. To stop any major deterioration of the product, an alkali solution was used. Ethanol has been found to aid the hydroxide nucleophilic effect on ester bonds of PLA. Then, the conditioned PLA was soaked with deionized water and eventually dried overnight under $\mathrm{N}_{2}$ gas flow in inert conditions.

\subsubsection{Preparation of the Sol-Gel Solutions for Coating on the Substrate Surface}

In the sol-gel process, polymer choice is important, depending on the target analytes' polarity/functionality. Taking into account the target analytes' physicochemical characteristics (Table 1), two sol-gel sorbents were prepared, including polyethylene glycol 300 (PEG 300) and poly(ethylene glycol)-block-poly(propylene glycol)-block-poly(ethylene glycol) 5.800 (PEG-PPG-PEG 5.800). Sol-gel solutions consist of a solvent system, a sol-gel precursor, an organic polymer, and an aqua solution of the catalyst. In our study, both polymer solutions were developed using methyltrimethoxysilane (MTMS) as the sol-gel precursor, a trifluoroacetic acid (TFA) catalyst containing 5\% water, and a combination of acetone and dichloromethane $(50 / 50 \mathrm{v} / \mathrm{v})$ as the organic solvent. The molar ratio between polymer:precursor:organic solvent:catalyst was optimized and maintained at 0.5:0.2:1.0:0.5, respectively. 
Table 1. Structures and respective physico-chemical characteristics of target analytes.

\begin{tabular}{|c|c|c|c|c|}
\hline Analyte & Molecular Weight, g/mole & Chemical Structure & pKa & $\log K_{o w}$ \\
\hline Citalopram (CIT) & 324.39 & & 9.78 & 3.76 \\
\hline Clozapine (CLO) & 326.82 & & 7.50 & 3.23 \\
\hline Mirtazapine (MIRT) & 265.35 & & 7.70 & 2.90 \\
\hline Bupropion (BUP) & 239.74 & & 8.22 & 3.85 \\
\hline Sertraline (SERT) & 306.20 & & 9.48 & 5.10 \\
\hline
\end{tabular}

A modified version of a previously described procedure [37] was adopted for the preparation of the sol solution. Briefly, $5 \mathrm{~g}$ of PEG 300 was dissolved in $5 \mathrm{~mL}$ of methyltrimethoxysilane (MTMS, sol-gel precursor). The mixture was then vortexed $(1 \mathrm{~min})$. Following this, $10 \mathrm{~mL}$ of the mixture of acetone/dichloromethane in ratio 50/50 v/v (solvent) was added, and then was vortexed again for $1 \mathrm{~min}$. After that, $2 \mathrm{~mL}$ of TFA catalyst was added. MTMS is hydrolyzed by the addition of the catalyst, and a network of the hydrolyzed MTMS molecules is created through the polycondensation. While the sol-gel network is growing, the chosen polymer incorporates randomly into it. The entire mixture was then vortexed ( $5 \mathrm{~min}$ ) and centrifuged for $5 \mathrm{~min}$ at $5000 \mathrm{rpm}$, and the transparent sol solution supernatant was moved to another clean flask. The fabric media were immersed there for $4 \mathrm{~h}$. The coated material was separated from the sol-gel solution and was held overnight in a desiccator for solvent evaporation. The sol-gel-coated FPSE device was then rinsed as a final move with a profuse amount of the organic solvent (acetone/dichloromethane: 50/50 v/v) under constant sonication for $30 \mathrm{~min}$ to remove unreacted and unbonded residual coating ingredients from the fabric surface. The sol-gel-coated fabric was then cut into 1-cm diameter circular pieces and placed in a sealed container so that unwanted analytes from the atmosphere did not accumulate. The successful preparation of the whole process was confirmed by FTIR analysis (Figure S1).

\subsection{Fabric Phase Sorptive Extraction Process}

First, the coated materials were soaked for $5 \mathrm{~min}$ in $2 \mathrm{~mL}$ of methanol:acetonitrile (1:1) solution, and next were treated with $2 \mathrm{~mL}$ deionized water for $5 \mathrm{~min}$ to remove the previous organic solvents. This step was conducted to clean and activate the coating of the fabric substrate. Afterwards, the FPSE media were immersed in the aquatic sample. Adsorption studies were conducted (spiking level $100 \mu \mathrm{g} \cdot \mathrm{L}^{-1}$, Milli-Q water, continuous stirring at $300 \mathrm{rpm}$ provided by magnetic stir bar) with the appropriate fabrics to choose the one that could be most effective for the target compounds. After this, the target analytes were eluted from the media in a sufficient volume of solvent for an optimal period. The collected solvent was adjusted to $100 \mu \mathrm{L}$ with a gentle $\mathrm{N}_{2}$ stream, before HPLC analysis. The schematic procedure of FPSE is shown in Figure S2.

\section{Results and Discussion}

\subsection{Selection of FPSE Substrate and Sol-Gel Coating}

The selectivity of the extraction depends on the hydrophilic/hydrophobic properties of the media and on the polarity of the polymer, which, together, define the extraction performance of the FPSE 
device. A Milli-Q water solution spiked (at $100 \mu \mathrm{g} \cdot \mathrm{L}^{-1}$ ) with the five antidepressant drugs was prepared to determine the efficiency of the process $(\mathrm{N}=3)$. The concentration of the analytes was measured by HPLC-UV-Vis/DAD before and after the extraction step, as well as after the elution step, in order to determine the adsorption and desorption efficiency, respectively. The performance of extraction was calculated as the ratio of the initial aqueous concentration in the Milli-Q water sample to the final concentration.

During preliminary studies, in which the type and shape of substrate as well as the polymer used in the creation of the sol-gel solution were tested, we decided to assess the following three different substrates: Whatman microfiber glass filter (FG), Whatman cellulose filter (WC), and polylactic acid disks (PLA). Two different sol-gel coatings were developed, high-polarity PEG 300 and medium-polarity PEG-PPG-PEG 5.800, which were finally evaluated. From the results obtained, it was found that the circle-shaped $100 \%$ glass microfiber filter (FG) with a diameter of $1 \mathrm{~cm}$ coated with PEG300 displayed the greatest adsorption and desorption yields, so this combination was chosen for further optimization.

\subsection{Optimization of the Experimental Conditions}

\subsubsection{Preliminary Experiments}

For the optimization of the FPSE process, both univariate and multivariate analysis approaches were carried out to encourage sound, rational thinking and responsibility instead of 'push-the-button' automated data. There are many variables that may influence FPSE extraction efficiency, among them are sample volume, ionic strength, $\mathrm{pH}$, extraction time and the solvent, as well as the elution solvent, time and volume, etc. Four of them were initially investigated to check their suitability to efficiently recover the target analytes: sample volume (1 and $10 \mathrm{~mL})$, extraction time (10, 20, 30 and $40 \mathrm{~min})$, $\mathrm{pH}(3,7,10$ and 12$)$ and ionic strength of the sample $(0 \%$ and $10 \% w / v)$.

The volume of the aqueous sample as well as the final volume of the extract are closely related to the technique's preconcentration ability. Two sample volumes $(1$ and $10 \mathrm{~mL})$ with a fixed elution volume solvent $(1 \mathrm{~mL}, \mathrm{MeOH})$ were examined initially under continuous stirring at $300 \mathrm{rpm}$ by a magnetic stir bar. The rate of adsorption for $1 \mathrm{~mL}$ was higher than for $10 \mathrm{~mL}$ (Figure 1a) for a fixed adsorption time of $10 \mathrm{~min}$, so $1 \mathrm{~mL}$ was selected to reach faster equilibrium conditions.

The extraction time is directly associated with the distribution parameters that determine the interaction between the FPSE material and the analytes. Four extraction times were investigated: 10, 20, 30 and $40 \mathrm{~min}$. The results revealed that extraction times of 10 and 20 min were marginally worse than longer extraction times of 30 and $40 \mathrm{~min}$ (Figure $1 \mathrm{~b}$ ). It can be seen that, after $30 \mathrm{~min}$, the equilibrium is established, so $30 \mathrm{~min}$ was chosen as the optimum extraction time.

For the $1 \mathrm{~mL}$ sample and 30 min extraction time, four separate $\mathrm{pH}$ values were measured: $\mathrm{pH} 3$, 710 and 12. At the alkaline $\mathrm{pH}$ region $(\mathrm{pH} 12)$ the highest extraction efficiency was obtained for all target analytes (Figure 1c). Considering the fact that the analytes act as weak bases (pKas are in the range between 7.5-9.8, Table 1), they are positively charged at environmentally relevant $\mathrm{pH}$ values, while, at $\mathrm{pH}$ values two units higher than their $\mathrm{pKa}(\mathrm{pKa}+2)$, they are in neutral form. This explains the higher adsorption yield that is observed at alkaline $\mathrm{pH}$ levels ( $\mathrm{pH} 12$ ). 


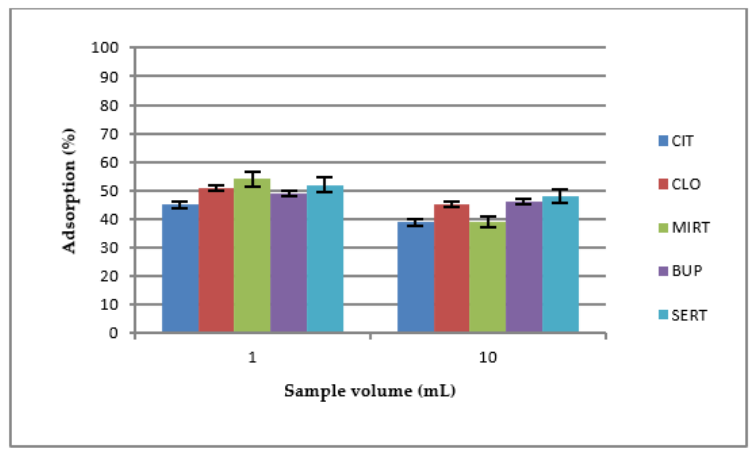

(a)

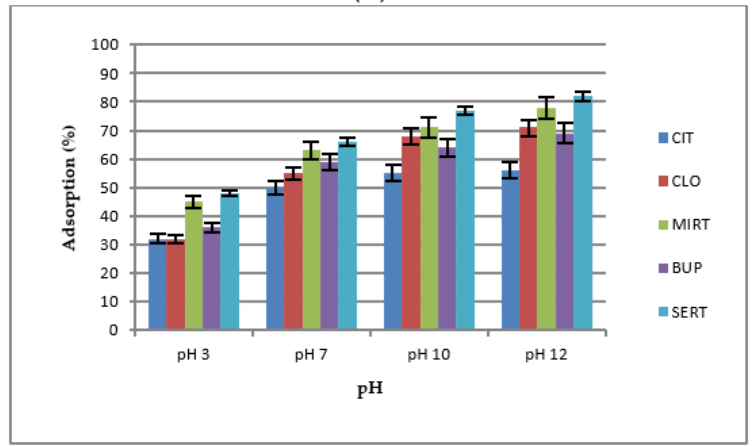

(c)

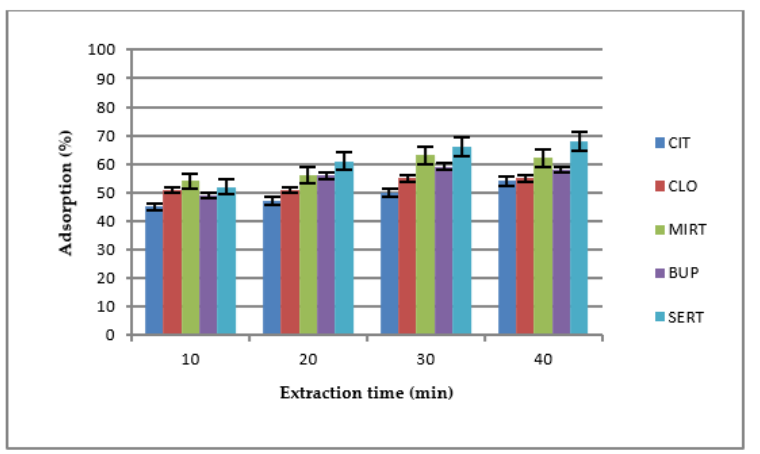

(b)

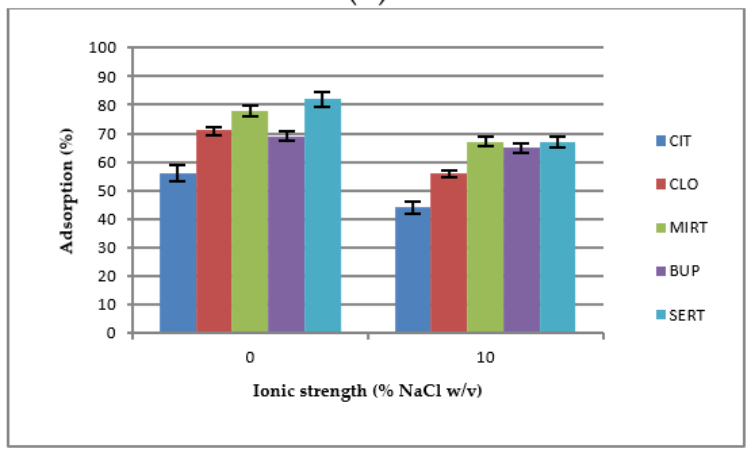

(d)

Figure 1. Efficiencies of the five antidepressants (ADs) during the adsorption step depending on (a) the volume of the sample, (b) extraction time for 10, 2030 and 40 min under stirring, (c) different pH values, and (d) ionic strength; citalopram (CIT), clozapine (CLO), mirtazapine (MIRT), bupropion (BUP), sertraline (SERT).

An increased concentration of ions in a solution is advantageous for increasing the recovery of organic contaminants from aqueous solution. The effect of ionic strength on analyte adsorption was studied, while the remaining parameters were fixed $(1 \mathrm{~mL}$ sample volume, $30 \mathrm{~min}$ of extraction and $\mathrm{pH}$ adjusted at 12). For this reason, $10 \%(w / v)$ of $\mathrm{NaCl}$ was added to the aqueous solution containing analytes (Figure 1d). The results have shown that the adsorption efficiency declines with increasing ionic strength. The decreased adsorption efficiency may be attributed to the increase in the aqueous matrix's viscosity, resulting in a sluggish distribution of analytes to the FPSE media.

\subsubsection{Experimental Design Optimization}

In the next step, we decided to select the appropriate elution variables to build a model that best reflected the variation of the microextraction process. The elution procedure was optimized through chemometric tools such as Design of Experiments (DoE) and Response Surface Methodology (RSM) (STATISTICA Software v7). The experimental configuration was initially conducted with four variables (two levels for each) to define how these affect the extraction performance (elution solvent: $\mathrm{MeOH} / \mathrm{ACN}$, elution process: vortex/stirring, elution time: $3 / 6 \mathrm{~min}$, elution volume $0.1 / 0.5 \mathrm{~mL}$ ). Methanol was far more efficient than $\mathrm{ACN}$, followed by stirring at $300 \mathrm{rpm}$ against a vortex as the desorption process, while both a higher elution time and solvent volume had a positive effect on the efficiency of the FPSE process (Figure 2). 


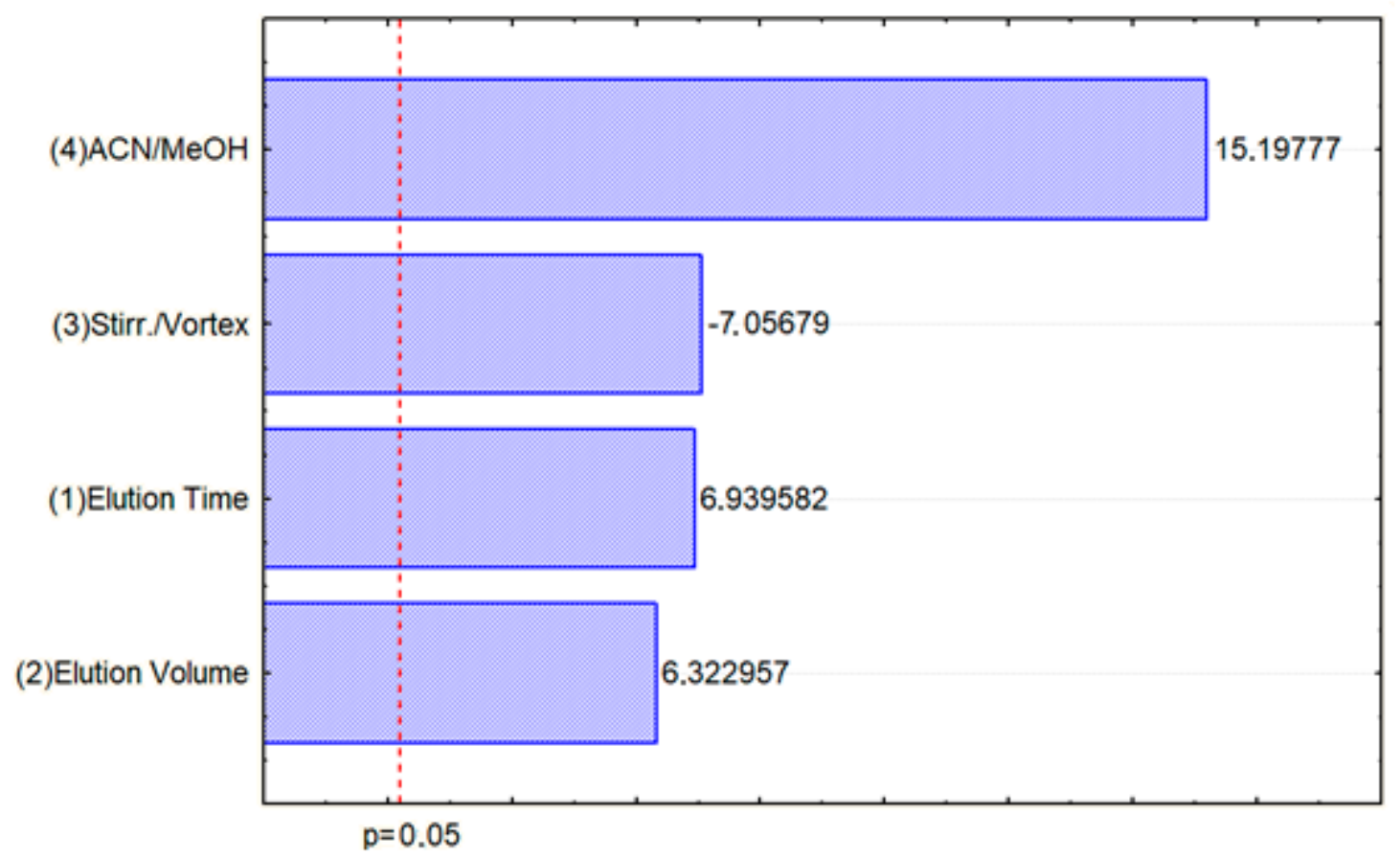

Figure 2. Pareto maps of the standardized effects ( $2^{4}$ experimental configuration).

Having followed the findings of the previous design, the next task was to improve the analytical process further by employing a $3^{2}$ experimental configuration for an elution volume of $\mathrm{MeOH}(0.75$, 1.00 and $1.25 \mathrm{~mL}$ ) and time $(5,10$ and $15 \mathrm{~min})$. The main effects were analyzed, as well as quadratic and interaction effects, by ANOVA (Table 2) and proved to be significant. The expressed a 3D correlation between the $\mathrm{MeOH}$ volume and the elution time, which is depicted in Figure 3. In particular, a higher elution time was needed when a greater amount of $\mathrm{MeOH}$ was used. A desirability function was used to determine the optimum extraction conditions (Figure 4).

Table 2. ANOVA results obtained by $3^{2}$ design.

\begin{tabular}{cccccc}
\hline Factor & SS & df & MS & F & p \\
\hline (1) Elution Time & 741.745 & 1 & 747.745 & 48.1578 & 0.000025 \\
(2) Elution Volume & 615.784 & 1 & 615.784 & 39.9798 & 0.000057 \\
(3) Stirring/Vortex mixing & 767.013 & 1 & 767.013 & 49.7983 & 0.000021 \\
(4) ACN/MeOH & 3557.526 & 1 & 3557.526 & 230.9724 & 0.000000 \\
Error & 169.426 & 11 & 15.402 & & \\
Total SS & 5851.495 & 15 & & & \\
\hline
\end{tabular}




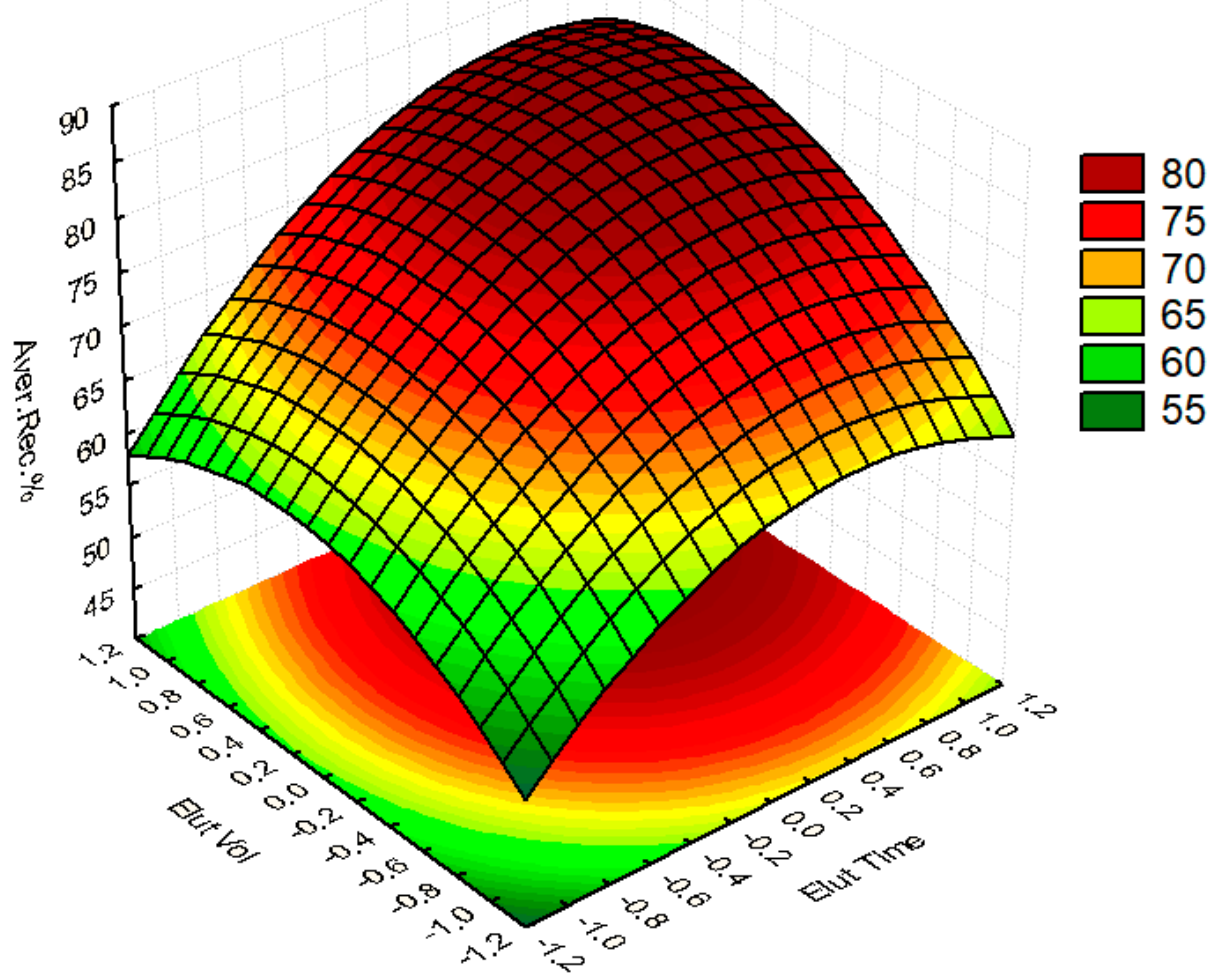

Figure 3. 3D Response Surface representation of elution time and solvent volume (coded values).
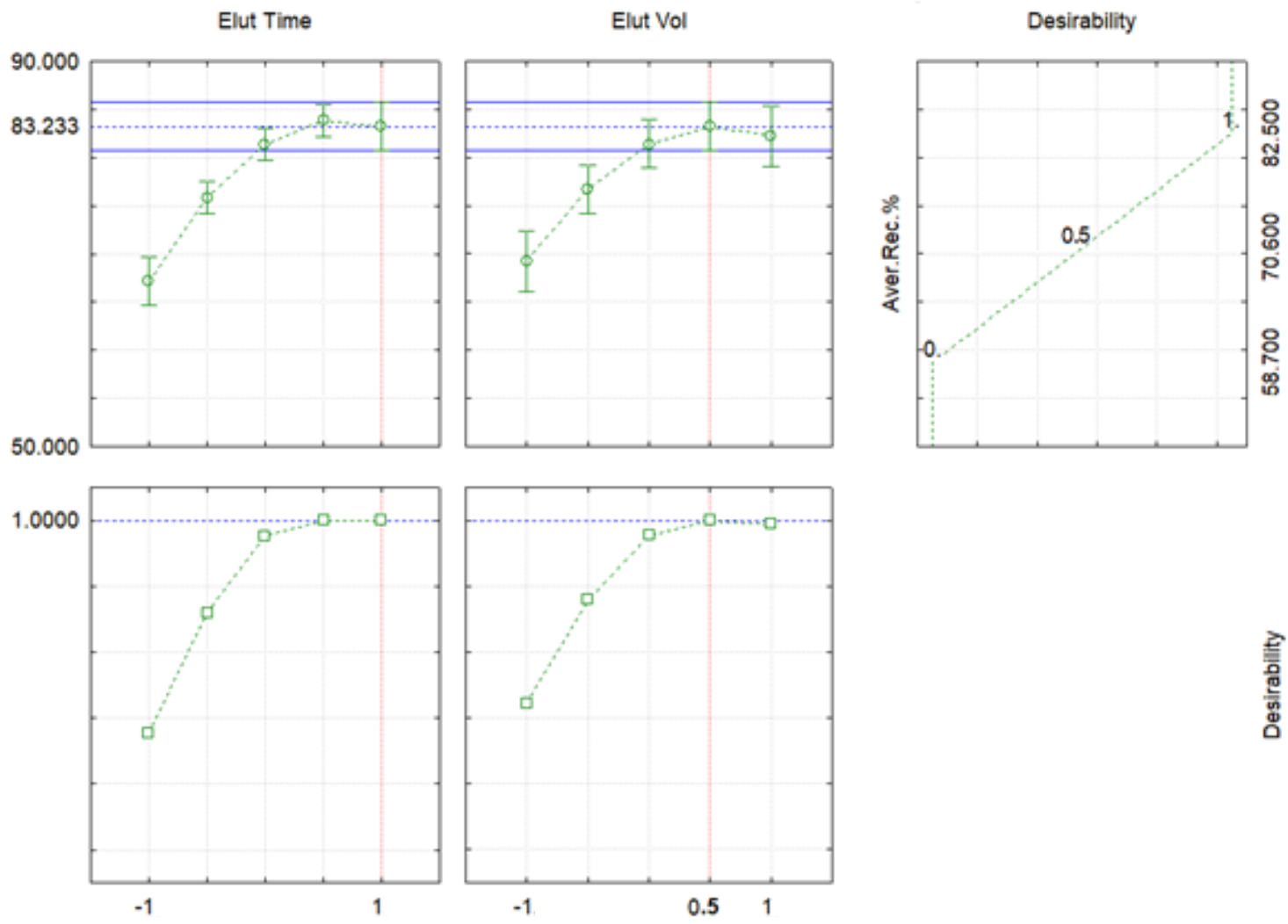

Figure 4. Desirability profiles and predict levels (coded values). 
To conclude, the optimal parameters for the FPSE process in relation to the extraction of the selected antidepressants were as follows: a circle-shaped $100 \%$ glass microfiber filter (FG) with a diameter of $1 \mathrm{~cm} \mathrm{c}$, with PEG300, as the FPSE device. The extraction of the aqueous sample $(1 \mathrm{~mL}$, adjusted to $\mathrm{pH}$ 12) was carried out for $30 \mathrm{~min}$ and stirred at $300 \mathrm{rpm}$. Methanol was used as the desorption solvent at $1.0 \mathrm{~mL}$ for $10 \mathrm{~min}$ under stirring at $300 \mathrm{rpm}$. The final extract was adjusted to $0.1 \mathrm{~mL}$ before analysis to have a preconcentration factor of 10 (from $1 \mathrm{~mL}$ to $0.1 \mathrm{~mL}$ ).

\subsection{Analytical Performance}

The figures of merit of the proposed method were also assessed. A seven-point curve was developed among the LOQ of each analyte up to $500 \mu \mathrm{g} \cdot \mathrm{L}^{-1}$. The method displays linearity at the specified range with coefficients of determination $\left(R^{2}\right)$ greater than 0.9989 . An examination of accuracy and precision was carried out at two concentration levels (LOQ and $10 \times \mathrm{LOQ}$ ) in Milli-Q water, spiked with the target analytes. The intraday precision of the process was measured through three assessments, while the interday precision was measured over three days by a triplet of measures. As depicted at Table 3, satisfactory absolute recoveries (the \% concentration of target analytes recovered from Milli-Q water) in the range of $60-98 \%$ were observed. The $\%$ RSDs were less than $13 \%$ in both cases.

Table 3. Analytical parameters of Milli-Q water samples $(n=3)$.

\begin{tabular}{|c|c|c|c|c|c|c|c|c|}
\hline \multirow{2}{*}{ Analyte } & \multirow{2}{*}{$\operatorname{LOD} \mu \mathrm{g} \cdot \mathrm{L}^{-1}$} & \multirow{2}{*}{ LOQ $\mu \mathrm{g} \cdot \mathrm{L}^{-1}$} & \multicolumn{2}{|c|}{ Recovery (\%) } & \multicolumn{2}{|c|}{ Intraday RSD (\%) } & \multicolumn{2}{|c|}{ Interday RSD (\%) } \\
\hline & & & LOQ & $10 \times$ LOQ & LOQ & $10 \times$ LOQ & LOQ & $10 \times \mathrm{LOQ}$ \\
\hline Citalopram (CIT) & 1.13 & 3.39 & 61.94 & 69.31 & 2.91 & 2.40 & 5.49 & 3.99 \\
\hline Clozapine (CLO) & 0.64 & 1.92 & 70.70 & 77.50 & 2.94 & 2.41 & 5.40 & 3.96 \\
\hline Mirtazapine (MIRT) & 3.22 & 10.71 & 76.34 & 83.08 & 6.92 & 5.87 & 8.39 & 12.63 \\
\hline Bupropion (BUP) & 2.05 & 6.82 & 71.77 & 75.70 & 4.22 & 4.08 & 10.79 & 7.41 \\
\hline Sertraline (SERT) & 1.12 & 3.36 & 79.71 & 98.10 & 2.38 & 4.34 & 4.28 & 6.76 \\
\hline
\end{tabular}

The method's LOD and LOQ were determined using a signal-to-noise ratio of three and 10, respectively. LODs ranged between 0.64 to $3.22 \mu \mathrm{g} \cdot \mathrm{L}^{-1}$ (Table 3).

\subsection{Applications in Environmental Samples}

Two wastewater samples from hospital and municipal WWTP effluents and a surface water sample from Pamvotis Lake were investigated to assess the applicability of the proposed method. However, there concentration levels of the target analytes were lower than the established LODs, or antidepressants were absent during this sampling campaign. These water samples were spiked with the selected ADs at $50.0 \mu \mathrm{g} \cdot \mathrm{L}^{-1}$, to confirm the efficiency of the process. A representative chromatogram is shown in Figure 5. Relative recoveries in real water samples were estimated from absolute recoveries of the Milli-Q water samples (relative recovery is defined as the \% concentration of target analytes recovered from the wastewater and surface water with reference to the concentration found in the spiked Milli-Q water). Depending on the water matrix and the analyte, relative recoveries varied between 69 and 121\% (Table 4). 


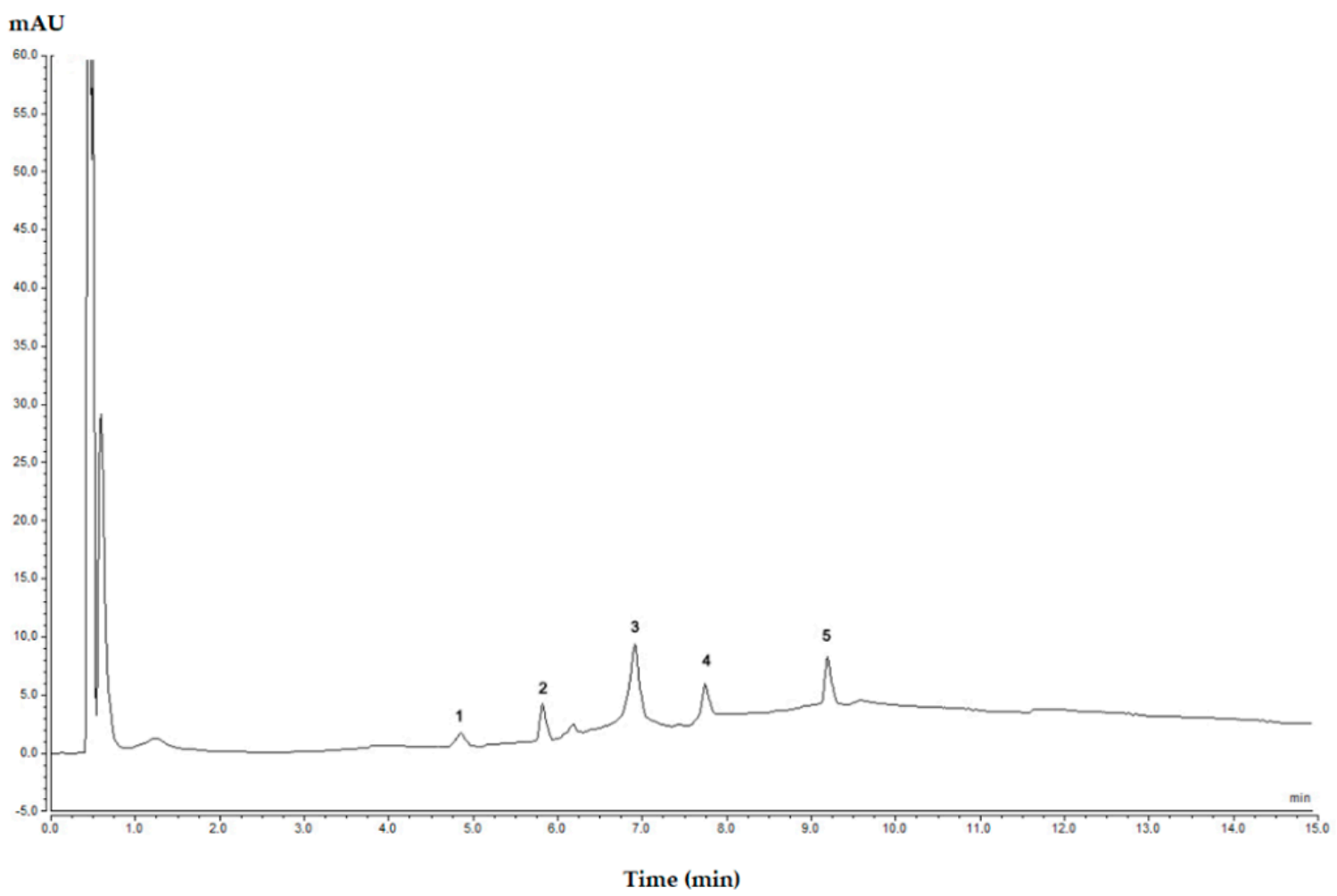

Figure 5. A representative chromatogram obtained from Lake water spiked at $50.0 \mu \mathrm{g} \cdot \mathrm{L}^{-1}$, after FPSE procedure coupled with High-Performance Liquid-Chromatography-Photodiode Array Detection (FPSE-HPLC-DAD) (1. MIRT, 2. BUP, 3. CLO, 4. CIT, 5. SERT).

Table 4. Analytical parameters of hospital and urban effluents and surface water samples $(n=3)$.

\begin{tabular}{|c|c|c|c|c|c|c|}
\hline \multirow{3}{*}{ Analyte } & \multicolumn{2}{|c|}{ Lake Water } & \multicolumn{2}{|c|}{ Hospital Effluent } & \multicolumn{2}{|c|}{ Urban Effluent } \\
\hline & \multicolumn{2}{|c|}{$50.0 \mu \mathrm{g} \cdot \mathrm{L}^{-1}$} & \multicolumn{2}{|c|}{$50.0 \mu \mathrm{g} \cdot \mathrm{L}^{-1}$} & \multicolumn{2}{|c|}{$50.0 \mu \mathrm{g} \cdot \mathrm{L}^{-1}$} \\
\hline & $\begin{array}{c}\text { Absolute } \\
\text { Recovery (\%) }\end{array}$ & $\begin{array}{c}\text { Relative } \\
\text { Recovery (\%) }\end{array}$ & $\begin{array}{c}\text { Absolute } \\
\text { Recovery (\%) }\end{array}$ & $\begin{array}{c}\text { Relative } \\
\text { Recovery (\%) }\end{array}$ & $\begin{array}{c}\text { Absolute } \\
\text { Recovery (\%) }\end{array}$ & $\begin{array}{c}\text { Relative } \\
\text { Recovery (\%) }\end{array}$ \\
\hline Citalopram (CIT) & 65.37 & 100.57 & 81.94 & 116.06 & 72.92 & 112.18 \\
\hline Clozapine (CLO) & 74.99 & 111.36 & 56.18 & 86.43 & 60.04 & 92.37 \\
\hline Mirtazapine (MIRT) & 101.34 & 104.07 & 99.01 & 120.75 & 107.86 & 113.34 \\
\hline Bupropion (BUP) & 65.93 & 93.16 & 53.46 & 75.54 & 49.18 & 69.49 \\
\hline Sertraline (SERT) & 69.07 & 107.60 & 61.22 & 94.20 & 56.14 & 86.38 \\
\hline
\end{tabular}

\section{Conclusions}

The study presented above is the first attempt to introduce the procedure of Fabric Phase Sorptive Extraction to extract and pre-concentrate five ADs contained in aqueous environmental samples. The aim of our study was not to reach the highest sensitivity of the methodology, otherwise different preconcentration factors and more sensitive analytical techniques (ultra-high performance liquid chromatography coupled to high resolution mass spectrometry, UPLC-HRMS) would have been employed. FPSE proved to be an easy, green and fast analytical method for the determination of the selected psychoactive drugs by employing HPLC-UV-Vis/DAD at concentration levels that may occur in natural aquatic systems $\left(\mu \mathrm{g} \cdot \mathrm{L}^{-1}\right)$. The most significant variables affecting the efficiency of the process were optimized by employing different experimental configurations. The proposed method is reproducible with good RSDs and acceptable recoveries in Milli-Q and real water samples, respectively. In addition, the method was applied in real water samples (hospital and urban effluents and Pamvotis Lake samples), but no ADs were detected. The future aim of the research team is to investigate different substrate/sorbent combinations in order to produce a FPSE device that would extract a broader 
number of pharmaceuticals and employ a more sensitive analytical technique (UPLC-HRMS) for their determination.

Supplementary Materials: The following are available online at http://www.mdpi.com/2297-8739/7/3/39/s1, Figure S1: FT-IR spectra of different components in (a) Whatman uncoated material, (b) PEG-PPG-PEG polymer, (c) MTMS precursor and (d) Whatman PEG-PPG-PEG coated media, Figure S2: General procedure applied in FPSE extraction.

Author Contributions: Conceptualization, C.J.-H. and V.S. (Vasilios Sakkas); methodology, C.J.-H., C.C., V.S. (Vassilis Stathopoulos) and V.S. (Vasilios Sakkas), software, C.J.-H. and V.S. (Vasilios Sakkas); validation, C.J.-H., C.C., investigation, C.J.-H., C.C., V.S. (Vassilis Stathopoulos) and V.S. (Vasilios Sakkas), writing-original draft preparation, C.J.-H., and C.C.; writing-review and editing, C.J.-H, C.C., V.S. (Vassilis Stathopoulos) and V.S. (Vasilios Sakkas); supervision, V.S. (Vassilis Stathopoulos) and V.S. (Vasilios Sakkas). All authors have read and agreed to the published version of the manuscript.

Funding: This paper is part of a project that has received funding from the European Union's Horizon 2020 research and innovation programme under the Marie Skłodowska-Curie grant, agreement no. 765860.

Conflicts of Interest: The authors declare no conflicts of interest.

\section{References}

1. Vardanyan, R.; Hruby, V.; Vardanyan, R.; Hruby, V. Antidepressants. In Synthesis of Best-Seller Drugs, 1st ed.; Academic Press: Tucson, AZ, USA, 2016; pp. 111-143. [CrossRef]

2. Schultz, M.M.; Furlong, E.T.; Kolpin, D.W.; Werner, S.L.; Schoenfuss, H.L.; Barber, L.B.; Blazer, V.S.; Vajda, A.M. Antidepressant pharmaceuticals in two U.S. effluent-impacted streams: Occurrence and fate in water and sediment and selective uptake in fish neural tissue. Environ. Sci. Technol. 2010, 44, 1918-1925. [CrossRef] [PubMed]

3. Lajeunesse, A.; Smyth, S.A.; Barclay, K.; Sauvé, S.; Gagnon, C. Distribution of antidepressant residues in wastewater and biosolids following different treatment processes by municipal wastewater treatment plants in Canada. Water Res. 2012, 46, 5600-5612. [CrossRef] [PubMed]

4. Golovko, O.; Kumar, V.; Fedorova, G.; Randak, T.; Grabic, R. Seasonal changes in antibiotics, antidepressants/psychiatric drugs, antihistamines, and lipid regulators in a wastewater treatment plant. Chemosphere 2014, 111, 418-426. [CrossRef] [PubMed]

5. Matongo, S.; Birungi, G.; Moodley, B.; Ndungu, P. Occurrence of selected pharmaceuticals in water and sediment of Umgeni River, KwaZulu-Natal, South Africa. Environ. Sci. Pollut. Res. 2015, 22, 10298-10308. [CrossRef] [PubMed]

6. Moghadam, A.G.; Rajabi, M.; Asghari, A. Efficient and relatively safe emulsification microextraction using a deep eutectic solvent for influential enrichment of trace main anti-depressant drugs from complicated samples. J. Chromatogr. B 2018, 1072, 50-59. [CrossRef]

7. Jannesar, R.; Zare, F.; Ghaedi, M.; Daneshfar, A. Dispersion of hydrophobic magnetic nanoparticles using ultarsonic-assisted in combination with coacervative microextraction for the simultaneous preconcentration and determination of tricyclic antidepressant drugs in biological fluids. UltrasonSonochem 2016, 32, 380-386. [CrossRef] [PubMed]

8. Safari, M.; Shahlaei, M.; Yamini, Y.; Shakorian, M.; Arkan, E. Magnetic framework composite as sorbent for magnetic solid phase extraction coupled with high performance liquid chromatography for simultaneous extraction and determination of tricyclic antidepressants. Anal. Chim. Acta 2018, 1034, 204-213. [CrossRef]

9. Degreef, M.; van Nuijs, A.L.; Maudens, K.E. Validation of a simple, fast liquid chromatography-tandem mass spectrometry method for the simultaneous quantification of 40 antidepressant drugs or their metabolites in plasma. Clin. Chim. Acta 2018, 485, 243-257. [CrossRef] [PubMed]

10. Breaud, A.R.; Harlan, R.; Kozak, M.; Clarke, W. A rapid and reliable method for the quantitation of tricyclic antidepressants in serum using HPLC-MS/MS. Clin. Biochem. 2009, 42, 1300-1307. [CrossRef] [PubMed]

11. Vaghar-Lahijani, G.; Saber-Tehrani, M.; Aberoomand-Azar, P.; Soleimani, M. Extraction and determination of two antidepressant drugs in human plasma by dispersive liquid-liquid microextraction-HPLC. J. Anal. Chem. 2018, 73, 145-151. [CrossRef] 
12. Ide, A.H.; Nogueira, J.M.F. New-generation bar adsorptive microextraction (BA $\mu \mathrm{E})$ devices for a better eco-user-friendly analytical approach-Application for the determination of antidepressant pharmaceuticals in biological fluids. J. Pharm. Biomed. Anal. 2018, 153, 126-134. [CrossRef] [PubMed]

13. Ragab, G.H.; Bahgat, E.A. Development of bioanalytical HPLC method for simultaneous determination of the antialzhiemer, donepezil hydrochloride and the antidepressant, citalopram hydrobromide in raw materials, spiked human plasma and tablets dosage form. Ann. Pharm. Françaises 2019, 77, 112-120. [CrossRef] [PubMed]

14. Boumba, V.A.; Rallis, G.; Petrikis, P.; Vougiouklakis, T.; Mavreas, V. Determination of clozapine, and five antidepressants in human plasma, serum and whole blood by gas chromatography-mass spectrometry: A simple tool for clinical and postmortem toxicological analysis. J. Chromatogr. B 2016, 1038, 43-48. [CrossRef] [PubMed]

15. Chen, X.; Zheng, S.; Le, J.; Qian, Z.; Zhang, R.; Hong, Z.; Chai, Y. Ultrasound-assisted low-density solvent dispersive liquid-liquid microextraction for the simultaneous determination of 12 new antidepressants and 2 antipsychotics in whole blood by gas chromatography-mass spectrometry. J. Pharm. Biomed. Anal. 2017, 142, 19-27. [CrossRef] [PubMed]

16. Kamaruzaman, S.; Sanagi, M.M.; Yahaya, N.; Wan Ibrahim, W.A.; Endud, S.; Wan Ibrahim, W.N. Magnetic micro-solid-phase extraction based on magnetite-MCM-41 with gas chromatography-mass spectrometry for the determination of antidepressant drugs in biological fluids. J. Sep. Sci. 2017, 40, 4222-4233. [CrossRef] [PubMed]

17. Jagtap, P.K.; Tapadia, K. Pharmacokinetic determination and analysis of nortriptyline based on GC-MS coupled with hollow-fiber drop-to-drop solvent microextraction technique. Bioanalysis 2018, 10, 143-152. [CrossRef] [PubMed]

18. Truta, L.; Castro, A.L.; Tarelho, S.; Costa, P.; Sales, M.G.F.; Teixeira, H.M. Antidepressants detection and quantification in whole blood samples by GC-MS/MS, for forensic purposes. J. Pharm. Biomed. Anal. 2016, 128, 496-503. [CrossRef]

19. Plenis, A.; BaCzek, T. Modern chromatographic and electrophoretic measurements of antidepressants and their metabolites in biofluids. Biomed. Chromatogr. 2011, 25, 164-198. [CrossRef]

20. Fernández, P.; Taboada, V.; Regenjo, M.; Morales, L.; Alvarez, I.; Carro, A.M.; Lorenzo, R.A. Optimization of ultrasound assisted dispersive liquid-liquid microextraction of six antidepressants in human plasma using experimental design. J. Pharm. Biomed. Anal. 2016, 124, 189-197. [CrossRef] [PubMed]

21. Rani, S.; Malik, A.K.; Kaur, R.; Kaur, R. A Review for the Analysis of Antidepressant, Antiepileptic and Quinolone Type Drugs in Pharmaceuticals and Environmental Samples. Crit. Rev. Anal. Chem. 2016, 46, 424-442. [CrossRef]

22. Song, A. Determination of 13 organic toxicants in human blood by liquid-liquid extraction coupling high-performance liquid chromatography tandem mass spectrometry. Anal. Sci. 2016, 32, 645-652. [CrossRef] [PubMed]

23. Juan, H.; Zhiling, Z.; Huande, L. Simultaneous determination of fluoxetine, citalopram, paroxetine, venlafaxine in plasma by high performance liquid chromatography-electrospray ionization mass spectrometry (HPLC-MS/ESI). J. Chromatogr. B 2005, 820, 33-39. [CrossRef] [PubMed]

24. Zilfidou, E.; Kabir, A.; Furton, K.G.; Samanidou, V. An improved fabric phase sorptive extraction method for the determination of five selected antidepressant drug residues in human blood serum prior to high performance liquid chromatography with diode array detection. J. Chromatogr. B 2019, 1125, 121720. [CrossRef] [PubMed]

25. Lioupi, A.; Kabir, A.; Furton, K.G.; Samanidou, V. Fabric phase sorptive extraction for the isolation of five common antidepressants from human urine prior to HPLC-DAD analysis. J. Chromatogr. B 2019, 1118, 171-179. [CrossRef]

26. Kabir, A.; Furton, K.G. Fabric Phase Sorptive Extractors (FPSE). U.S. Patent No. 9,283,544, 15 March 2016.

27. Kabir, A.; Furton, K.G.; Malik, A. Innovations in sol-gel microextraction phases for solvent-free sample preparation in analytical chemistry. Trends Anal. Chem. 2013, 45, 197-218. [CrossRef]

28. Aznar, M.; Alfaro, P.; Nerin, C.; Kabir, A.; Furton, K.G. Fabric phase sorptive extraction: An innovative sample preparation approach applied to the analysis of specific migration from food packaging. Anal. Chim. Acta 2016, 936, 97-107. [CrossRef] 
29. Karageorgou, E.; Manousi, N.; Samanidou, V.; Kabir, A.; Furton, K.G. Fabric phase sorptive extraction for the fast isolation of sulfonamides residues from raw milk followed by high performance liquid chromatography with ultraviolet detection. Food Chem. 2016, 196, 428-436. [CrossRef] [PubMed]

30. Santana-Viera, S.; Guedes-Alonso, R.; Sosa-Ferrera, Z.; Santana-Rodríguez, J.J.; Kabir, A.; Furton, K.G. Optimization and application of fabric phase sorptive extraction coupled to ultra-high performance liquid chromatography tandem mass spectrometry for the determination of cytostatic drug residues in environmental waters. J. Chromatogr. A 2017, 1529, 39-49. [CrossRef]

31. Kumar, R.; Gaurav; Kabir, A.; Furton, K.G.; Malik, A.K. Development of a fabric phase sorptive extraction with high-performance liquid chromatography and ultraviolet detection method for the analysis of alkyl phenols in environmental samples. J. Sep. Sci. 2015, 38, 3228-3238. [CrossRef]

32. Montesdeoca-Esponda, S.; Sosa-Ferrera, Z.; Kabir, A.; Furton, K.G.; Santana-Rodríguez, J.J. Fabric phase sorptive extraction followed by UHPLC-MS/MS for the analysis of benzotriazole UV stabilizers in sewage samples. Anal. Bioanal. Chem. 2015, 407, 8137-8150. [CrossRef]

33. Lakade, S.S.; Borrull, F.; Furton, K.G.; Kabir, A.; Marcé, R.M.; Fontanals, N. Dynamic fabric phase sorptive extraction for a group of pharmaceuticals and personal care products from environmental waters. J. Chromatogr. A 2016, 1456, 19-26. [CrossRef] [PubMed]

34. Lakade, S.S.; Borrull, F.; Furton, K.G.; Kabir, A.; Fontanals, N.; Marcé, R.M. Comparative study of different fabric phase sorptive extraction sorbents to determine emerging contaminants from environmental water using liquid chromatography-tandem mass spectrometry. Talanta 2015, 144, 1342-1351. [CrossRef] [PubMed]

35. Luzanin, O.; Movrin, D.; Stathopoulos, V.; Pandis, P.; Radusin, T.; Guduric, V. Impact of processing parameters on tensile strength, in-process crystallinity and mesostructure in FDM-fabricated PLA specimens. Rapid Prototyp. J. 2019, 25, 1398-1410. [CrossRef]

36. Pandis, P.K.; Papaioannou, S.; Koukou, M.K.; Vrachopoulos, M.G.; Stathopoulos, V.N. Differential scanning calorimetry based evaluation of 3D printed PLA for phase change materials encapsulation or as container material of heat storage tanks. Energy Procedia 2019, 161, 429-437. [CrossRef]

37. Kumar, R.; Malik, A.K.; Kabir, A.; Furton, K.G. Efficient analysis of selected estrogens using fabric phase sorptive extraction and high-performance liquid chromatography-fluorescence detection. J. Chromatogr. A 2014, 1359, 16-25. [CrossRef] [PubMed]

(C) 2020 by the authors. Licensee MDPI, Basel, Switzerland. This article is an open access article distributed under the terms and conditions of the Creative Commons Attribution (CC BY) license (http://creativecommons.org/licenses/by/4.0/). 